\title{
COMO CRIANÇAS PEQUENAS LEEM LIVROS DE IMAGEM?
}

\author{
FABIANA ANDRADE DE SANTANA \\ Ana Carolina Perrusi Brandão \\ Universidade Federal de Pernambuco (UFPE), Recife, Pernambuco, \\ Brasil
}

\begin{abstract}
Resumo: O estudo investigou a leitura de livros de imagem por crianças entre quatro e cinco anos. As narrativas produzidas pelos pequenos foram videogravadas e transcritas. Com base nesse material foram formuladas categorias de análise que orientaram a discussão dos dados. Aos cinco anos, as crianças tendem a produzir narrativas que apresentam maior fidelidade à sequência das imagens e incluem mais inferências pertinentes. Aos quatro anos, as narrativas são menos articuladas, com predominância de descrição das cenas. $\mathrm{O}$ estudo apontou, entretanto, que o progresso das crianças em direção a uma leitura mais articulada não parece ser fruto, simplesmente, do avanço com relação à idade. Assim, discute-se a necessidade de refletir sobre formas de mediação de livros de imagem na educação infantil.
\end{abstract}

Palavras-chave: Leitura. Livro de imagem. Desenvolvimento infantil. Educação infantil.

INTRODUÇÃO

Quando se observa a leitura de livros de imagem na Educação Infantil constatamos que comumente os pequenos ficam restritos à escuta da leitura feita pelo adulto. Entendemos, porém, que o livro de imagem pode se 
constituir em uma excelente oportunidade para que as crianças exerçam um papel mais ativo na produção de sentidos. Nessa direção, o presente estudo investigou as possibilidades de leitura de narrativas visuais por crianças entre quatro e cinco anos. Sobre esse tema, Castanha (2008, p. 145) destaca que

[...] não podemos chegar a acreditar que para compreender e decodificar o mundo nos bastam somente os textos, a palavra escrita. A escola pode ser também espaço, para, no mínimo, desenvolver o interesse por outras linguagens, o que certamente contribuirá para que seus alunos se tornem leitores mais críticos e observadores não só de textos e imagens, mas de um conjunto de formas expressivas e do próprio mundo em que vivem.

A mesma autora também adverte que "a maioria dos adultos, sejam eles pais ou professores, não consegue esconder certo desconforto ao lidar com livros de imagens". (CASTANHA, 2008, p. 145). Entendemos que, possivelmente, isto reflete uma falta de familiarização com esse tipo de livro, bem como de conhecimento sobre o fascínio que as narrativas visuais podem provocar nos pequenos leitores.

Nesse sentido, outro ponto a ser destacado é a postura adotada durante a leitura dessas narrativas no contexto escolar. De fato, muitos professores parecem não saber como mediar a leitura de livros de imagem e ignoram as potencialidades presentes nessas obras. Observações informais indicam que tal desconhecimento gera mediações inadequadas, imposições de interpretações pelo professor e avaliações errôneas sobre o interesse que as crianças teriam pela leitura desses livros.

Consideramos, no entanto, que a entrada da literatura no cotidiano escolar deve incluir o encontro das crianças com livros contendo narrativas não apenas escritas, mas também visuais. Nessa perspectiva, buscamos explorar este tema, partindo dos seguintes objetivos: (1) Observar se crianças de quatro e cinco anos demonstram interesse pela leitura de livros de imagem; (2) Investigar se, durante a leitura, as crianças descrevem as imagens do livro de forma isolada ou se produzem uma narrativa que tenta articular a sequência de imagens presente no livro; (3) Analisar se há diferenças entre crianças na faixa etária investigada com respeito aos dois itens anteriores; (4) Identificar e analisar que elementos/ comentários (tais como: inferências 
ou elementos imaginativos e lúdicos) são destacados ou agregados pelas crianças durante a sua leitura.

\section{A LITERATURA INFANTIL NA EDUCAÇÃO DE CRIANÇAS MENORES DE SEIS ANOS}

Tal como ressalta Fernandes (2011), na escola, a literatura é muitas vezes utilizada ora como pretexto para ensinar aspectos gramaticais, ora para introduzir o ensino de virtudes e boas condutas. Na Educação Infantil esse segundo aspecto parece ser bastante enfatizado buscando-se, frequentemente, moralizar os pequenos e induzir formas de comportamento padronizadas por meio da literatura.

Além disso, muitas vezes, ignora-se a importância de estabelecer um horário diário para a leitura na escola e de conduzir uma "conversa reflexiva" que possibilite as crianças produzir significados sobre o que foi lido (BRANDÃO; ROSA, 2010). Assim, como destacado por Martins (2007), durante ou após a leitura, observa-se não raramente uma expectativa de respostas uniformes por parte das crianças, que confirmem a interpretação do texto lido, segundo apenas a perspectiva da professora.

Ao contrário dessa proposta, assim como Riter (2009) e Cosson (2014), temos defendido (BRANDÃO; ROSA, 2011) a necessidade do ambiente escolar ser planejado de modo a favorecer o letramento literário e a formação de leitores ativos e críticos desde a Educação Infantil.

O PAPEL DO LIVRO DE IMAGEM PARA O DESENVOLVIMENTO INFANTIL E PARA A FORMAÇÃO DO LEITOR

Quando pensamos na importância da literatura para a formação do leitor, as narrativas verbais são imediatamente indicadas como ferramentas essenciais no contexto escolar. Porém, entendemos que os livros de imagem também são indispensáveis nesse processo. De fato, como salienta Oliveira (2009, p. 169), "o texto visual não tem merecido lugar entre as leituras apresentadas na escola. Sendo assim, a alfabetização estética das crianças tem sido relegada, para dar lugar a uma alfabetização voltada somente para a aquisição do código escrito." 
Concordando com a referida autora, também consideramos que é fundamental estimular a participação da criança em experiências de leitura diversificadas ampliando sua familiaridade com diferentes estilos, temas e gêneros literários, incluindo os livros de imagem.

Nesse sentido, a exploração das narrativas visuais pode possibilitar o desenvolvimento de competências importantes para ampliar a sensibilidade das crianças em relação a como as imagens se apresentam e representam a realidade. Afinal, participamos de uma sociedade imersa em diferentes tipos e formas de imagens presentes nas revistas, nos jornais, na televisão, nas ruas e em diversos outros espaços, que provocam sentimentos e ações diversas (CASTANHA, 2008).

Consideramos, ainda, que os livros com as narrativas visuais podem constituir-se em ferramentas para estimular o interesse das crianças pelos livros e pela leitura. Como sabemos, as imagens atraem os pequenos antes do texto escrito possibilitando, assim, que eles construam suas próprias histórias, ampliando sua capacidade de expressão verbal. Como já afirmamos aqui, o contato com livros de imagem esteticamente bem construídos certamente também favorece o desenvolvimento de um olhar mais atento e crítico em relação ao que veem no mundo.

Nessa direção, assim como Borba e Mattos (2011, p. 222), entendemos que a leitura desses livros:

[...] exige capacidades de observação, atenção, concentração e contribui para o desenvolvimento do conhecimento abstrato, do raciocínio, da imaginação; daí ser necessário desafiarmos as crianças, desde muito cedo, a explorar, tanto de forma autônoma quanto de forma dirigida, livros de imagem, especialmente aqueles que trazem elementos e personagens que vão ao encontro de seus interesses e curiosidades.

A possibilidade que os livros de imagem oferecem para o desenvolvimento da imaginação indicada acima merece ser destacada. Como sabemos, quanto maior for a pluralidade de experiências vividas pelas crianças, mais significativa e fértil será sua atividade imaginativa. A respeito da imaginação Vigotski (2009, p. 25), acrescenta que ela "transforma-se em meio de ampliação da experiência de um individuo porque, tendo por base a narração ou a 
descrição de outrem, ele pode imaginar o que não viu, o que não vivenciou diretamente em sua experiência pessoal".

É possível afirmar-se, portanto, que o processo imaginativo constitui-se como primordial para o desenvolvimento e formação do seres humanos. Dessa forma, ao intermediar o encontro das crianças com livros de imagem, estamos contribuindo para que as mesmas potencializem seu imaginário e desenvolvam-se intelectualmente.

Ressaltamos, entretanto, que para que isso ocorra é fundamental que esses livros tenham valor artístico-estético, o que significa, segundo Borba e Mattos (2011, p. 216), garantir às crianças "[...] o contato com imagens não-esterotipadas, não padronizadas, originais, sugestivas, significativas, complexas. São essas imagens que deixam espaço para criança pensar". Nessa perspectiva, o acesso a livros de imagem de boa qualidade constitui um passo importante no longo processo de formação de leitores interessados e capazes de dialogar com os textos verbais ou não verbais de forma, cada vez mais, ativa e crítica.

\section{A PRODUÇÃO DE NARRATIVAS POR CRIANÇAS PEQUENAS E OS LIVROS DE IMAGEM}

Diversas pesquisas indicam que crianças muito pequenas já se mostram capazes de produzir histórias ou recontá-las. Araújo (2009), por exemplo, mostrou que crianças de cinco e seis anos recontam histórias ouvidas inventando e recriando episódios. O estudo de Brandão (1994), que explorou a produção e compreensão de histórias num grupo de 60 crianças com quatro, seis e oito anos, também indicou que já aos quatro anos, muitas crianças produzem histórias coerentes. A partir do mote "conte uma história de uma flor que vivia triste num jardim", a autora solicitou que as crianças inventassem uma história que foi gravada e posteriormente analisada. Considerando o grupo de 20 crianças de quatro anos, embora $40 \%$ delas afirmem que não sabem inventar uma história ou produzam um texto com enunciados desarticulados, $25 \%$ das crianças produzem uma narrativa seguindo uma sequência temporal de eventos; $20 \%$ produzem uma narrativa com estrutura causal, isto é, uma historia que apresenta as causas para a tristeza da flor; e $15 \%$ já conseguem construir um episódio simples. Isto é, que inclui um 
cenário, uma situação problema (a tristeza da flor) e um desfecho (a solução para o problema).

Diferentemente do estudo de Brandão (1994), na situação de produção de narrativa proposta na presente pesquisa, a criança é chamada a compreender a sequência de imagens apresentada no livro. Assim, ela não está inteiramente "livre" para elaborar sua história, sendo o foco do estudo investigar, exatamente, como se dá esse processo de produzir uma narrativa com base na leitura das imagens de um livro.

Esse também foi o objetivo do estudo de Bissoli (2007). Na pesquisa, crianças de cinco anos e meio e seis anos de idade foram solicitadas a ler um dos seguintes livros de imagem: "Filó e Marieta", de Eva Furnari e "Ida e Volta" de Juarez Machado. A autora buscou compreender como as crianças realizavam a leitura de imagem e que operações intelectuais eram colocadas em jogo durante o processo de leitura. Participaram 19 crianças de uma sala de Pré III, da rede municipal de ensino de Rio Claro (SP), sendo dez meninos e nove meninas. Dentre as crianças, dez leram Filó e Marieta e nove leram Ida e volta. Para o registro das leituras foi utilizado um gravador e um diário de campo onde foram anotados alguns aspectos do comportamento das crianças durante a sessão de leitura.

As sessões foram divididas em dois momentos distintos: leitura silenciosa, em que as crianças eram solicitadas a olhar as imagens do livro e, em seguida, a leitura oral, em que se pedia que ela "lesse" o livro apresentado. Durante essas leituras, a pesquisadora buscou intervir minimamente na narrativa produzida pelas crianças. Assim, ela se limitava a perguntar sobre o que as crianças viam nas imagens apenas ao perceber pausas prolongadas durante a leitura dos livros ou quando as próprias crianças solicitavam alguma ajuda.

As narrativas produzidas foram categorizadas pela autora em três níveis descritos da seguinte forma: Nível A - produções de narrativas coerentes, isto é com começo, meio e fim; Nível B - descrição das cenas que compõem a obra; Nível C - narrações em que a pesquisadora foi o suporte para a construção da narrativa. Isto é, quando a pesquisadora ajudava a criança com estímulo para a leitura do livro. 
Considerando os resultados na leitura dos dois livros de imagem, do total das 19 crianças que participaram do estudo, nove $(47,3 \%)$ apresentaram uma produção de narrativa coerente (nível A), seis $(31,05 \%)$ apresentaram uma leitura descritiva das imagens (nível B) e quatro $(21,05 \%)$ produziram narrativas com a intervenção do adulto.

Ao analisar seus dados, Bissoli (2007) concluiu que a leitura de narrativas visuais desenvolve e exercita o raciocínio e promove a elaboração de inferências. Ainda segundo sua análise, os dados indicam que a verbalização da mensagem visual requisitou das crianças um trabalho de reconstrução do pensamento e de estruturação das ideias para entender as imagens, com base em suas vivências e conhecimentos anteriores.

Vale salientar que embora o estudo de Bissoli (2007) tenha objetivos semelhantes aos da presente pesquisa, alguns pontos distinguem os dois estudos. Em primeiro lugar, trabalhamos com um grupo de crianças mais novas (entre quatro e cinco anos). Além disso, cada criança leu dois livros o que torna possível fazer uma análise mais aprofundada da leitura de cada sujeito. Outra diferença importante diz respeito à mediação da pesquisadora durante a leitura. No estudo de Bissoli (2007), buscou-se deliberadamente intervir o mínimo possível. Como foi dito, "as perguntas e estímulos" da pesquisadora para a construção da narrativa só se fizeram presentes após longos períodos de pausa das crianças ou após seu pedido explícito de ajuda. No presente estudo, optamos, ao contrário, por aproximar a situação de pesquisa a um contexto mais natural quando se lê livros de imagem com crianças em casa ou na escola. Assim, a interação com a pesquisadora foi constante por meio da formulação de perguntas sobre o que a criança via nas imagens do livro ou sobre o que poderia acontecer mais adiante ou ainda com a formulação de questões que buscavam ampliar sua narrativa.

A seguir, explicitaremos em mais detalhes os procedimentos metodológicos adotados na pesquisa.

\section{Metodologia}

Para alcançar os objetivos propostos, realizamos a coleta de dados com crianças frequentando duas instituições públicas de Educação Infantil 
do Recife que incluíam em sua rotina atividades de leitura e contação de histórias. Entendemos que a familiarização com essas práticas poderia possibilitar uma maior interação das crianças com as pesquisadoras, propiciando um clima mais favorável para a interação com os pequenos durante a leitura dos livros de imagem.

Após um contato inicial com as duas escolas e com as crianças dos Grupos 4 e 5, convidamos algumas delas para fazer a leitura de dois livros de imagem. As crianças foram chamadas individualmente, não havendo um critério predeterminado para a escolha dos sujeitos. O Quadro 1, abaixo, dá informações sobre os 12 participantes do estudo.

Quadro 1: Informações sobre os participantes da pesquisa

\begin{tabular}{ccccc}
\hline \multirow{2}{*}{ Idade } & \multicolumn{2}{c}{ Escola A } & \multicolumn{2}{c}{ Escola B } \\
\cline { 2 - 5 } & Meninos & Meninas & Meninos & Meninas \\
\hline 4 anos & & $\mathrm{C} 3, \mathrm{C} 6, \mathrm{C} 7$, & $\mathrm{C} 8, \mathrm{C} 9$ & $\mathrm{C} 10, \mathrm{C} 11$ \\
\hline 5 anos & $\mathrm{C} 1, \mathrm{C} 4$ & $\mathrm{C} 2, \mathrm{C} 5$ & $\mathrm{C} 12$ & \\
\hline
\end{tabular}

Nota: $\mathrm{C}=$ criança

Embora não tenha sido o foco da pesquisa, durante as visitas à escola A constatamos a presença de uma sala de leitura com livros de boa qualidade e que era bastante frequentada pelas crianças. Na escola B também havia uma biblioteca com um acervo vasto e com obras de boa qualidade, inclusive com livros de imagem. Porém, o espaço estava trancado e era usado, na verdade, como depósito para os livros e materiais de limpeza. Nas salas das crianças da escola B também não havia livros de literatura disponíveis. Os livros ficavam guardados no armário da professora e só eram retirados no momento em que ela lia para as crianças.

A leitura dos livros de imagem ocorreu numa sala da escola e enquanto uma das pesquisadoras interagia com a criança, a outra se responsabilizava pelo vídeo gravação. Tal como destaca lbiapina (2008), por meio do vídeo tornou-se possível obter um registro mais detalhado e fidedigno dos dados, de modo a ampliar nossas possibilidades de análise do processo de leitura de cada criança. 
Antes de solicitarmos a leitura das duas narrativas, buscamos motivar as crianças para a atividade, chamando sua atenção para a ilustração da capa do livro. Também lemos o titulo e os nomes dos autores. Em seguida, fizemos o convite: "você lê esse livro pra mim?". Durante a leitura, quando a criança ficava em silêncio diante de alguma página, a pesquisadora perguntava: "o que está acontecendo aqui?". Algumas vezes, perguntas mais específicas eram formuladas. Por exemplo:"e quem tá brincando com os bonequinhos?" ou "e ela fez o quê, com a varinha dela?" Como destacado anteriormente, por meio dessa participação ativa da pesquisadora, buscamos promover um contexto de leitura mais familiar, bem como manter a atenção das crianças na atividade. Além disso, as perguntas formuladas visavam esclarecer ou ampliar a narrativa que as crianças iam construindo, instigando-as a pensar e a perceber aspectos importantes não observados nas ilustrações e que poderiam contribuir para a produção de sentidos.

Para a pesquisa foram utilizados os seguintes títulos: “Viagem a vapor" de Regina Rennó (Belo Horizonte: Ed. Abacate, 2009) e a "Bruxinha Zuzu e o gato Miú" de Eva Furnari (São Paulo: Ed. Moderna, 2010). Os dois livros passaram pelo crivo de qualidade do Programa Nacional Biblioteca da Escola (PNBE), sendo indicados para a etapa da Educação Infantil. O primeiro fez parte do acervo do PNBE de 2010 e o segundo do acervo de 2012.

Vale frisar que as duas obras apresentam uma sugestão de narrativa que instiga a participação e curiosidade dos leitores, estimulando sua interação com as imagens. Ambas também obedecem a uma estrutura linear em que há, claramente, uma história sugerida na sequência de imagens apresentadas.

O livro Viagem a vapor inicia com duas crianças que, aparentemente, fazem uma viagem num barco. Veem crocodilos, hipopótamos, grandes matas, castelos e, em terra, andando por uma floresta, deparam-se com um dragão voando no céu, um leão, um elefante e uma onça. Amedrontados, voltam ao barco. Nas últimas páginas do livro percebe-se que o barco a vapor estava, na verdade, numa bacia com água onde um menino e uma menina (os mesmos personagens que aparecem navegando no barco ao longo da história) brincavam com um barquinho na água. Ao redor da bacia vê-se 
ainda o castelo, árvores e bichinhos de plástico (leão, dragão, etc.), ou seja, os mesmos animais encontrados durante a "arriscada aventura" dos dois garotos. Infere-se, portanto, que "a viagem no barco a vapor" foi, na verdade, uma brincadeira de faz de conta das crianças.

O livro "A bruxinha Zuzu e gato Miú" é composto por pequenas histórias que sempre incluem os dois personagens. Em cada página aparecem três quadrinhos com cenas diferentes e cada história é composta por seis quadrinhos. No presente estudo, as crianças foram solicitadas a ler apenas a primeira história que dá título ao livro. Nesse episódio, a bruxinha resolve presentear Miú com um pulôver de tricô feito por ela mesma. O pulôver, porém, ficou claramente maior do que o tamanho do gato. Zuzu, então, utiliza sua varinha mágica para aumentar o seu amigo de tamanho e Miú não parece ter gostado dessa solução.

Os livros foram apresentados às crianças sempre na seguinte ordem: Livro 1 (Bruxinha Zuzu e gato Miú) e Livro 2 (Viagem à vapor). Como foi dito, durante a leitura, uma das pesquisadoras interagia constantemente com a criança, sempre buscando manter seu interesse na atividade, formulando perguntas, levando-as a pensar e a observar as imagens sem, entretanto, construir a história por ela.

Ao término das sessões de leitura, realizamos a transcrição dos vídeos para posterior análise.

\section{A LEITURA DE NARRATIVAS VISUAIS SUGERIDAS EM LIVROS DE IMAGEM POR CRIAN- ÇAS DE QUATRO A CINCO ANOS}

Retomando os objetivos desse estudo, podemos dizer que as crianças mostraram-se atentas e engajadas na leitura dos livros de imagem disponibilizados. Por exemplo, durante a leitura da história Bruxinha Zuzu e Gato Miú, a criança 7 (quatro anos) imita a expressão facial de desagrado do gato ao receber o presente feito pela bruxinha. A criança 5 também reage diante da mudança da técnica das ilustrações presentes no livro "Viagem a vapor" que, em determinado ponto da narrativa, mistura desenhos e fotos na mesma página. Nesse momento, a criança interrompe a leitura que fazia e olhando para a imagem do livro pergunta à pesquisadora: "Por que tá di- 
ferente?!" (C4, cinco anos). Além disso, as manifestações de interesse pelas obras foram explicitadas corporalmente por todas as crianças participantes do estudo a partir dos seus olhares atentos e de algumas reações verbais de surpresa como, por exemplo:"Não tem letras?!... Por que não tem letras?" (C4) ou "Cadê as letras?" (C6). Finalmente, vale notar que nenhuma das crianças se negou a realizar a leitura das obras ou manifestou o desejo em abandoná-la antes de chegar ao final do livro. Assim, ao que parece Borba e Mattos (2011, p. 222) tem razão quando afirmam que

livros de imagens esteticamente bem construídos, especialmente aqueles que trazem elementos e personagens que vão ao encontro aos interesses e curiosidades das crianças, histórias que envolvam animais, por exemplo, geralmente são muito apreciadas.

De fato, concordamos que a participação ativa das crianças durante a leitura seja resultado da boa qualidade estética das obras selecionadas pelo PNBE e que foram utilizadas na pesquisa. Ressaltamos ainda que tais manifestações de interesse também se devam, certamente, à forma como a pesquisadora interagiu com as crianças. Na leitura do livro "Viagem a vapor", por exemplo, no momento em que aparece a mão de um dos personagens pegando o barco, a pesquisadora chama atenção da criança e pergunta: “O que aconteceu aqui? Que mão é essa?!" A criança vai para a página seguinte, retorna seu olhar para a página com a imagem da mão e responde: "essa é a mão dos meninos" (C1, cinco anos). Tais intervenções, assim como esperávamos, parecem ter contribuído não apenas para manter o engajamento dos pequenos durante a leitura, mas para fazê-los pensar sobre as imagens, ampliando a construção da sua narrativa, como ocorreu no exemplo acima.

Dando continuidade aos objetivos do presente estudo foi possível constatar três níveis de leitura com base nas narrativas produzidas pelas crianças a partir dos livros de imagem utilizados no estudo:

Nível 1 - narrações em que predomina a nomeação de elementos isolados presentes nas imagens do livro. Em alguns casos, observam-se acréscimos de informações, aparentemente, desconectadas com a sequência de imagens do livro. Exemplo (C8, quatro anos): 
C8- Barco! P- É um barco. E o barco tava onde? C8- Rio P- E aí o que foi que aconteceu? ... O que isso? C8- Jacaré! P- E aí? C8- Menina e menino P- A menina e o menino e o que eles estavam fazendo? C8- Hipopótamo. P- Hipopótamo. E agora o que aconteceu? C8- Castelo P- Certo, e depois? C8- Dragão P- O dragão, não foi? E agora o que aconteceu? C8- Leão P- Eles viram o leão, não foi? E agora? C8- Elefante P- E agora quem apareceu? C8Tigre P- Viram o tigre e ai o que aconteceu? C8- Correu P- Correram, não foi? C8- Barco P- barco? C8- menina e menino. P E aqui o que ta acontecendo? C8- Não sei P- O que aconteceu aqui? C8- Mão P- E essa mão fez o quê? C8Não sei! P-Olha direitinho o que tá acontecendo? C8- Bonequinhos P-E quem ta brincando com os bonequinhos? C8- Menino e menina.

Nível 2 - narrações predominantemente descritivas (fotográficas) das imagens do livro. Observam-se algumas tentativas de articulação temporal ou causal entre certas imagens, porém, nem sempre essa articulação é coerente com a narrativa sugerida no livro. Exemplo ( $C 5$, cinco anos):

C5-O barco e o mar. P- O barco e o mar. Então vai passando a folhinha e vai contando. $C 5$ - $O$ menino dentro do barco $P$ - Os meninos dentro do barco C5-Viajou e o jacaré nem ligou. P-Viajou né, e o jacaré nem ligando. E aí o que aconteceu? C5-E ele e ele ficou nadando, nadando P-Ficou nadando, nadando né? O hipopótamo né, e o nome desse bichinho aqui é hipopótamo. E agora o que aconteceu? C5-Teve um barcão e o menino tava pescando. P-Eles estavam pescando foi, aqui? C5- Foi! P- E aqui? (volta a página anterior... que não foi mencionada pela criança) C5- As árvore e o castelinho. [...] C5- E ele o dragão estava voando e a menina vê o dragão voando. P-O dragão estava voando e os meninos viram. C5- E o leão tava correndo e eles viram o leão. E eles não viram. E o elefante era bem maior. E tem o negócio aqui (referindo-se a tromba do elefante) P-A tromba do elefante, né? C5-E ele vendo outro bichinho, e a onça veio $\mathrm{P}$ - A onça veio não foi? C5- E ele. E ele nem ligava. P- Eles nem ligavam? E agora o que aconteceu? C5- É o barco de novo, eles subiram no barco e foi navegando e navegando. Eles entraram no mar e foi nadando, nadando... P-E ai, o que aconteceu aqui? C5- Eles tavam brincando (diante da imagem final dos meninos brincando com o barco numa bacia com água). 
Nível 3 - narrações que apresentam maior fidelidade às ideias sugeridas pelas imagens do livro. Nota-se uma maior preocupação de construir uma história, incluindo a elaboração de inferências pertinentes. Exemplo (C1, cinco anos):

C1- A bruxinha tava costurando um cachecol pro gato. P- Eu vou pedir pra tu tirar esse brinquedinho da boca pra gente poder ouvir. Ai o que aconteceu aqui? C1- A bruxa colocou ele no gato. P- E aqui o que aconteceu? C1-O gato nem gostou P- nem gostou, não foi? C1- Porque tava... tava grande demais. P- E aqui? O que aconteceu? C1- A bruxa disse que ele ia ficar ainda com ele... Porque, só que ele não gostava ainda mais P- E ela fez o quê aqui? C1- Fez um feitiço pro gato ficar grande pra combinar. P-Fez um feitiço pro gato ficar grande e combinar, não é? C - E ai acabou a historinha!

A Tabela 1, abaixo, apresenta a classificação das narrativas produzidas pelas crianças com base nos níveis de leitura indicados acima. Vejamos:

Tabela 1: Percentagem dos níveis de leitura por livro de imagem

\begin{tabular}{lcccc}
\hline \multicolumn{1}{c}{ Livros de imagem } & Nível 1 & Nível 2 & Nível 3 & $\begin{array}{c}\text { Total de } \\
\text { produções }\end{array}$ \\
\hline $\begin{array}{l}\text { Livro 1: Bruxinha Zuzu } \\
\text { e Gato Miú }\end{array}$ & $25 \%$ & $16,67 \%$ & $58,33 \%$ & 12 \\
\hline Livro 2: Viagem a vapor & $33,33 \%$ & $33,33 \%$ & $33,33 \%$ & 12 \\
\hline Percentual total & $29,2 \%$ & $25 \%$ & $46 \%$ & 24 \\
\hline
\end{tabular}

A distribuição dos dados apresentados na Tabela 1 mostra que o livro 1 (Bruxinha Zuzu e Gato Miú) foi lido pelas crianças com mais facilidade. Assim, considerando as 12 narrativas produzidas a partir deste livro, 25\% foram classificadas em um nível menos elaborado (nível 1), sendo esse percentual um pouco maior no livro 2 (33\%). No nível de leitura mais elaborado (nível 3), constatamos que a diferença entre os dois livros foi ainda maior. Ou seja, no livro $1,58 \%$ das leituras foram classificadas no nível 3, enquanto no livro 2 , apenas $33 \%$ das leituras atingiram o mesmo nível.

Tal resultado, possivelmente, se deve ao fato do primeiro livro ter menos imagens e elementos visuais quando comparado ao segundo que, além de apresentar um maior número de cenas (o que, em princípio, exi- 
giria uma maior atenção das crianças), traz um elemento surpresa ao final da narrativa que requer do leitor a elaboração de uma inferência complexa. Como dissemos acima, só nas últimas páginas do livro, percebe-se que toda a história era fruto da imaginação das duas crianças. Assim, a mão que, de repente, surge pegando o barco a vapor é, na verdade, de um dos meninos que, na página seguinte, brinca diante de uma bacia com água, o barquinho e outros brinquedos (o castelo, o dragão, o jacaré, entre outros) que aparecem ao longo do livro. Cabe ao leitor, portanto, desconstruir a narrativa que estava sendo formulada e dar significado aos novos elementos que aparecem no final do livro. No caso do livro 1, também é preciso inferir que a bruxa fez uma mágica e que aumentou o tamanho do gato para que o pulôver que havia feito pudesse caber no seu amigo Miú. Porém, consideramos que tal inferência é bem mais simples de ser construída, pois se articula com um conhecimento de mundo que certamente já faz parte do universo das crianças dessa faixa etária.

Voltando aos dados da Tabela 1, apresentada acima, vemos que não houve diferenças marcantes entre o desempenho dos sujeitos do estudo de Bissoli (2007) e os sujeitos mais novos da presente pesquisa. Como indicado anteriormente nos dados da autora, $47,3 \%$ das produções foram classificadas como narrativas coerentes (nível A). No presente estudo vimos na Tabela 1 que $46 \%$ do total das produções estavam no nível 3 . Ainda nos dados de Bissoli, 31,05\% das produções estavam associadas a uma leitura descritiva das imagens (nível B) e 21,05\% das narrativas necessitaram da intervenção do adulto para serem construídas. No caso do presente estudo, esses dados podem corresponder aos níveis 2 e 1 , respectivamente, ou seja, $25 \%$ e $29,2 \%$. Assim, considerando a diferença na faixa etária dos participantes das duas pesquisas, é possível supor que a constante intervenção do adulto durante a produção da leitura no presente estudo tenha favorecido o desempenho dos sujeitos mais novos.

Na Tabela 2 abaixo, reapresentamos os dados da Tabela 1, dessa vez de forma em que os níveis de leitura produzidos por cada sujeito são indicados nos dois livros utilizados na pesquisa. Vejamos abaixo como ficou a distribuição: 
Tabela 2: Níveis de leitura de cada criança por livro de imagem

\begin{tabular}{|c|c|c|c|c|}
\hline Livros de imagem & Nível 1 & Nível 2 & Nível 3 & $\begin{array}{l}\text { Total de } \\
\text { crianças }\end{array}$ \\
\hline $\begin{array}{l}\text { Livro 1: } \\
\text { Bruxinha Zuzu } \\
\text { e Gato Miú }\end{array}$ & $\mathrm{C} 8{ }^{*}, \mathrm{C} 9, \mathrm{C} 10$ & $\mathrm{C} 3, \mathrm{C} 5$ & $\begin{array}{c}\mathrm{C} 1, \mathrm{C} 2, \mathrm{C} 4, \mathrm{C} 6, \\
\mathrm{C} 7, \mathrm{C} 11, \mathrm{C} 12\end{array}$ & 12 \\
\hline $\begin{array}{l}\text { Livro 2: } \\
\text { Viagem a vapor }\end{array}$ & $\begin{array}{c}\text { C8, C9, } \\
\text { C10, C11 }\end{array}$ & $\begin{array}{l}\mathrm{C} 3, \mathrm{C} 5 \\
\mathrm{C} 7, \mathrm{C} 12\end{array}$ & $\mathrm{C} 1, \mathrm{C} 2, \mathrm{C} 4, \mathrm{C} 6$ & 12 \\
\hline
\end{tabular}

*Nota: C8 = leitura produzida pela criança 8; C9 = leitura produzida pela criança 9 e assim sucessivamente.

Como se pode ver na Tabela 2, nota-se uma tendência de que os sujeitos produzam narrativas no mesmo nível de leitura independentemente do livro de imagem lido. De fato, vemos que apenas a criança 11 fica no nível mais elementar de leitura no livro 2 e alcança o nível 3, mais elaborado, no livro 1. Tais dados apontam, portanto, para certa convergência em termos do desempenho de cada criança, mesmo considerando a diferença quanto à complexidade dos livros de imagem utilizados na pesquisa, tal como argumentamos acima.

Também vale observar que comparando os dados apresentados no Quadro 1 e na Tabela 2, vemos que as crianças que apresentaram uma produção de leitura mais articulada (níveis 2 e 3) frequentavam a escola A. Ou seja, aquela que nos pareceu oferecer mais acesso das crianças aos livros de literatura. É impossível, porém, fazer alguma afirmação acerca da influência positiva desse aspecto no desempenho das crianças já que os sujeitos mais velhos são justamente da escola $A$, tal como também podemos ver no Quadro 1. Assim, a idade constitui um aspecto a ser considerado.

Vejamos, abaixo, na Tabela 3, os níveis de leitura apresentados em função, exatamente, da idade das crianças:

Tabela 3: Percentagem dos níveis de leitura por idade das crianças

\begin{tabular}{cccc}
\hline Idade & Nível 1 & Nível 2 & Nível 3 \\
\hline 4 anos & $50 \%$ & $21,43 \%$ & $28,57 \%$ \\
\hline 5 anos & & $30 \%$ & $70 \%$ \\
\hline
\end{tabular}


Como é possível ver na Tabela 3, as narrativas classificadas no nível 1 foram produzidas exclusivamente pelas crianças de quatro anos. Pode-se afirmar, portanto, que a leitura do grupo mais novo tende a se concentrar nos níveis 1 e 2, enquanto as leituras das crianças de cinco anos tendem a ficar no nível mais elaborado. Entretanto, isso não pode ser visto como um padrão fixo. Como vemos nos dados da Tabela 2, apresentada anteriormente, a criança 6, por exemplo, produz uma narrativa no nível 3 nos dois livros e tem apenas quatro anos (ver Quadro 1). Por outro lado, a criança 5, embora tenha cinco anos, fica no nível 2 nos dois livros. Tais resultados indicam, portanto, que não é possível fazer uma associação direta entre idade e desempenho dos sujeitos. Ou seja, a qualidade das experiências de leitura que as crianças tem acesso também é um elemento que precisa ser considerado.

Retomando o último objetivo da pesquisa, a partir das produções realizadas foi possível identificar comentários e elementos agregados ao texto visual como a utilização de expressões de abertura e fechamento, comumente, presentes em contos de fada e que indicam certa familiarização com práticas de leitura de histórias. Por exemplo: "Era uma vez um barquinho..." e "foram felizes para sempre" (C4, cinco anos, Livro 2).

A inserção dessas expressões convencionais típicas na produção oral de histórias também foi identificada no estudo de Bissoli (2007) com crianças de cinco e seis anos e no estudo de Brandão (1994). No segundo estudo, $84.7 \%$ das histórias produzidas pelas crianças de quatro anos incluíam esses elementos; que apareciam também em $52.7 \%$ das histórias produzidas pelo grupo de seis anos, e em $84,3 \%$ das produções das crianças de oito anos. Porém, como ressalta Brandão (1994), a presença do recurso não estava, necessariamente, associada a produções de histórias em um nível mais elaborado.

Nas leituras das crianças da presente pesquisa observamos ainda a inserção de informações, isso é, acréscimos compatíveis às imagens apresentadas nos livros. Por exemplo: "veio o jacaré atacar o barco, tinha os meninos que tavam em perigo presos na água" ( $\mathrm{C} 1$, livro 2). Como se vê, a criança deduz o perigo que um jacaré representa para os dois personagens da história. No mesmo livro destacamos outro exemplo diante da cena em que os meninos 
retornam para o barco e continuam a viagem. Nesse momento, a criança 2 acrescenta: "foram lá pra cidade pra casa deles" ( $C 2$, cinco anos, livro 2).

Também identificamos na leitura da Bruxinha Zuzu e Gato Miú, a utilização de acréscimos compatíveis com a narrativa. Por exemplo, diante da imagem em que Zuzu está sentada com agulhas de tricô (ver a imagem abaixo), uma criança diz: "a bruxinha tava costurando um cachecol pro gato" (C1). Outra criança fala: "ela ta fazendo um vestido" (C11, quatro anos).

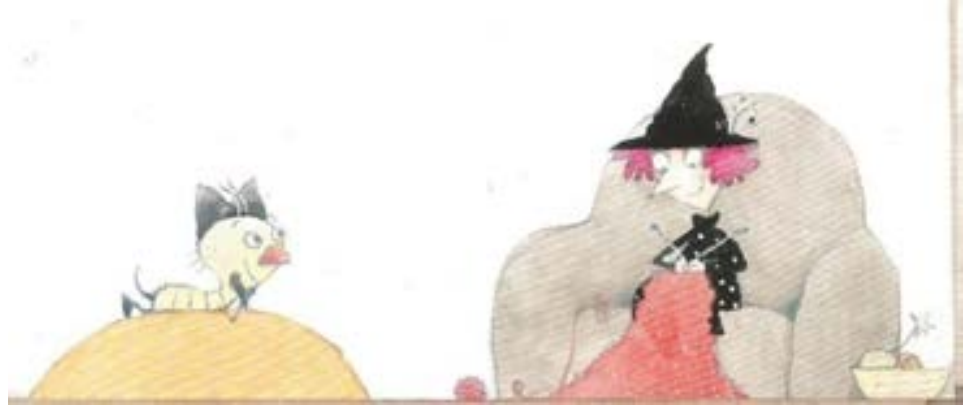

Figura 1: Bruxinha Zuzu e gato Miú, de Eva Furnari

Vale frisar que também foram observados acréscimos um tanto incompatíveis. Isso é, "não autorizados" pelas imagens. Por exemplo, diante da mesma cena apresentada acima, uma das crianças falou: "botou o gatinho pra dormir" (C5, livro 1). No entanto, as inserções ilustradas acima, quer sejam mais ou menos autorizadas, revelam que os pequenos, desde muito cedo, utilizam situações de sua experiência pessoal para ler as imagens do livro, tal como se espera de um leitor que ativamente busca construir sentidos. Nota-se ainda que as produções que alcançaram o nível 3 tendem a apresentar acréscimos mais compatíveis com as imagens. Por outro lado, as produções no nível 2 tendem a apresentar acréscimos, aparentemente, desconectados com a narrativa visual. Desse modo, quanto menos elaboradas as produções, maior parece ser a probabilidade de ocorrer acréscimos do segundo tipo.

Ao explorar as narrativas produzidas pelas crianças também buscamos perceber como a sequência de imagens de cada livro foi compreendida e as possíveis inferências elaboradas durante a leitura. A esse respeito foi 
observado que alguns sujeitos produziram inferências pertinentes e elaboradas. Por exemplo, durante a leitura do livro 2 (ver a sequência de imagens abaixo), na última página onde se vê duas crianças (as mesmas que vinham aparecendo dentro do barco a vapor, ao longo do livro), brincando com um barquinho numa bacia com água, o sujeito 1 (cinco anos) faz a seguinte leitura: "brincando... Eles só tão brincando com os brinquedos deles", parecendo indicar sua compreensão de que tudo não passava apenas de uma brincadeira de faz de conta.

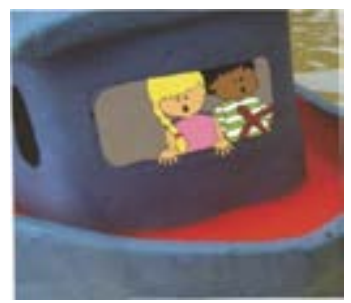

Figura 2. Viagem a vapor, de Regina Rennó.

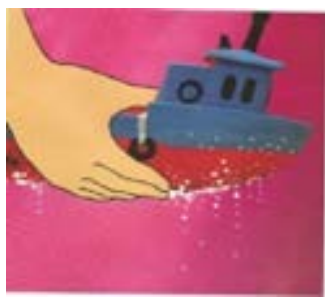

Figura 3. Viagem a vapor, de Regina Rennó.

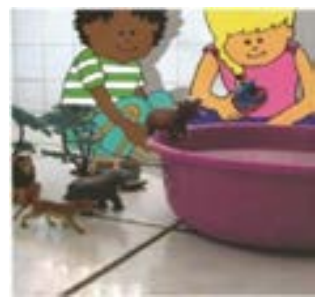

Figura 4. Viagem a vapor, de Regina Rennó.

Outro exemplo com relação a essa mesma sequência de imagens do livro 2 foi registrado na leitura da criança 7 (quatro anos). Vejamos o diálogo entre ela e a pesquisadora:

C - ... Fez: "Oh"! P- O que será que aconteceu? C7- Aconteceu uma coisa! (olhando a cena 2 da sequência acima) P- Qual foi a coisa? C7- Não sei. P- O que aconteceu aqui? (indicando no livro a cena 2) C7- Uma mão. P- Uma mão, não foi? E essa mão fez o quê? C7- Uma mão gigante! P- Uma mão gigante que apareceu, não foi? $\mathrm{E}$ aqui? (apontando para cena 3) $\mathrm{C7}-\mathrm{E}$ aí tava brincando com as coisa deles. P- Quem que brincou? C7- O menino e a menina. P- $O$ menino e menina brincaram com as coisas deles, não é? P - (a pesquisadora retorna à cena 2) $E$ esse barquinho aqui, é um barquinho de mentira ou um barquinho de verdade? C7- Barquinho de mentira. P-É de mentira? Por que que tu acha que é de mentira? C7- Porque eu acho!

Como é possível constatar, a criança 7 observa aspectos relevantes na sequência de imagens, tal como o espanto dos personagens dentro do 
barquinho que dizem "Oh!" diante da "mão gigante"e afirma ainda que o barco "é de mentira", ainda que não apresente uma justificativa elaborada para essa resposta. $O$ mesmo pode ser dito em relação à criança 4 (cinco anos) que infere que as crianças na cena 1 são "bonequinhos". Vejamos:

C4- Eles correram. P-Correram foi? C4-Depois eles voltaram pro barco P- Depois entram no barco e aí? E agora? C4- São bonequinhos... (olhando a cena 1 da sequência apresentada acima). P-São bonequinhos... como assim? C4- Aqui. (apontando a cena 1) P-Tô vendo. Como é que tu sabe? C4- Porque ta segurando o barco (olhando a cena 2). P- Segurou o barco, né, são bonequinhos. E agora o que aconteceu aqui?(apontando a cena 3) C4- Foram feliz para sempre! [...] P- (a pesquisadora retorna à imagem 2) Esse barquinho era de verdade? C4- Não. P- Era não? Como é que tu sabe que ele não era de verdade? C4- Porque é de brinquedo. P-Era de brinquedo, né, como é que tu sabe que o barquinho era de brinquedo? C4- Porque barco é de brinquedo! P- Por que o quê? C4- Porque barco é de brinquedo! P- Barco é de brinquedo, certo! C4- E foram felizes pra sempre!

A elaboração de inferências durante a leitura também foi registrada em relação ao livro 1. Na sequência de imagens abaixo, por exemplo, vemos na cena 2 que a bruxinha aponta a varinha em direção ao gato que vestia um pulôver grande demais, aparecendo várias estrelinhas e o gato em tamanho maior na cena 3. Diante dessas imagens a criança 1 (cinco anos) diz: "fez um feitiço pro gato ficar grande para combinar".

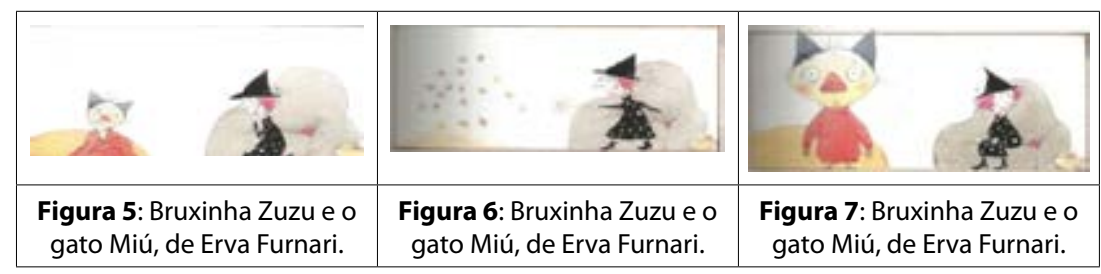

Nota-se que a criança inferiu corretamente a mágica da bruxinha para que o tamanho do gato combinasse com o tamanho do pulôver que ela havia feito para seu amigo. Na mesma sequência, uma criança mais nova também diz: "a bruxa fez uma mágica" ao ser questionada sobre qual foi a 
mágica, ela completa "foi pra o gato desaparecer, aí o gato cresceu e cabiu (sic) nele" (C6, quatro anos).

Ainda na mesma sequência, também constatamos, porém, alguns casos de ausência de uma elaboração inferencial. Por exemplo, na leitura do livro 1, a criança 8 (quatro anos) destaca as estrelinhas da cena 2, mas não consegue inferir o seu significado, registrando-se o seguinte diálogo: $\mathrm{P}$ - E aqui? (aponta a imagem 2 da sequência apresentada acima) $O$ que ela (a bruxa) fez? C8 - Estrelinhas. P - E por que ela fez essas estrelinhas? C8 - Não sei...

\section{CONSIDERAÇões FinaIS}

O estudo confirmou o interesse que crianças de quatro e cinco anos demonstram em produzir narrativas a partir dos livros de imagem e que é possível mediar a leitura desses livros de modo reflexivo e ativo com essa faixa etária. Também pudemos constatar que aos cinco anos, as crianças tendem a produzir leituras que apresentam maior fidelidade à sequência das imagens e incluem mais inferências pertinentes. Aos quatro anos, as leituras são menos articuladas, com predominância de descrição das imagens do livro. Porém, como foi argumentado, o progresso das crianças em direção a uma leitura mais articulada não parece ser fruto, simplesmente, do avanço com relação à idade.

A pesquisa apontou ainda a importância da mediação docente na leitura de livros de imagem, tendo em vista que essa mediação pode constituir-se não apenas como elemento motivador para o leitor, mas também como auxiliar na produção de sentidos do texto. Daí a relevância da professora planejar de forma mais aprofundada possíveis perguntas que podem ser formuladas diante de pontos mais complexos da narrativa e que exigem um maior trabalho inferencial dos pequenos leitores. Por exemplo, no livro "Viagem a vapor", utilizado no estudo, na cena em que aparece a mão pegando o barquinho, vimos a necessidade de experimentar e refletir sobre possíveis perguntas que podem melhor estimular as crianças a pensar e levantar hipóteses sobre o que está sendo sugerido pelas imagens. 
Finalmente, vale mencionar que, frequentemente, observamos um equívoco em relação à mediação de leitura com livros de imagem que é restringir a proposta desse tipo de livro para crianças não alfabetizadas. A ideia é que por serem livros sem escrita, supostamente, estariam mais indicados para essa fase inicial em que a criança ainda não lê convencionalmente. Como vimos aqui, as narrativas visuais não apresentam uma sequência de eventos, necessariamente, simples. Ao contrário, livros de imagem demandam, com frequência, um engajamento do leitor para a elaboração de inferências e construção de relações entre as cenas do livro de modo a produzir uma narrativa coerente. Assim, sob nosso ponto de vista, os bons livros de imagem destinam-se a qualquer idade.

Nessa perspectiva, ressaltamos a necessidade de pesquisas futuras sobre as práticas de mediação docente com os livros de imagem. Consideramos que esses livros se constituem em um caminho fascinante para grandes e pequenos leitores, oferecendo possibilidades de ampliar seu potencial crítico e capacidade de observação contribuindo, assim, para a formação de um leitor que pensa, compreende e aprecia o que lê.

Artigo recebido em: 30/06/2015 Aprovado para publicação em: 10/01/2016

\section{HOW DO CHILDREN READ PICTURE BOOKS?}

ABSTRACT: The study investigated wordless picture book reading by 4 - and 5-year-old children. The narratives constructed by them were videotaped and transcribed. Based on this material, categories of analysis were formulated and used to guide the discussion of the data. At age 5, children tend to produce narratives that have greater fidelity to the sequence of images and include more relevant inferences. At age 4, children's narratives are less articulated, consisting mostly of descriptions of the pictures in isolation. The study indicated, however, that children's progress towards more complex reading does not appear to occur simply as the result of age. Thus, the study points out the need to reflect on ways that teachers can mediate wordless-picture-book reading in early childhood education.

KEYWORDS: Reading. Picture books. Child development. Early childhood education. 


\section{¿CÓMO LEEN NIÑOS PEQUEÑOS LIBROS DE IMAGEN?}

Resumen: Este estudio investigó la lectura de libros de imagen en niños entre 4 y 5 años. Las narrativas producidas por los niños fueron grabadas en vídeo y transcritas. Ese material sirvió de base para formular las categorías de análisis que orientan la discusión de los datos. A los 5 años, los niños tienden a hacer lecturas que guardan mayor fidelidad con la secuencia de dibujos e incluyen inferencias más pertinentes. A los 4 años, las lecturas son menos articuladas, predominando la descripción de escenas en el aislamiento. Sin embargo, el estudio reveló que el desarrollo de los niños en dirección a una lectura más articulada no parece ser fruto, simplemente, del avance con relación a la edad. De esta forma, se discute la necesidad de reflexionar sobre formas de intermediar la lectura de libros con imágenes en la educación infantil.

Palabras-Clave: Lectura. Libros de imagen. Desarrollo del niño. Educación infantil.

\section{REFERÊNCIAS}

ARAÚJO, A. N. B. A narrativa oral literária na educação infantil: quem conta um conto aumenta um ponto. Tese (Doutorado em Educação) - Universidade Federal de Pernambuco, p.201. Recife, 2009.

BISSOLI, L. M. S. A leitura de imagens e indícios e a produção oral de textos por pré-escolares. In: Congresso de leitura do Brasil. In: Anais do 15a COLE, São Paulo, p. $71-$ 87. 2005.

BORBA, A. M; MATTOS, M. S. A leitura do livro de imagem com crianças de 0 a 6 anos: um convite à narrativa e à imaginação. In: GONÇALVES A. V.; PINHEIRO A. S. (Org.). Nas trilhas do letramento: entre teoria, prática e formação docente. 1. ed. Campinas, Mercado de Letras, 2011, p. 205-225.

BRANDÃO, A. C. P. Produção e compreensão de histórias em crianças. Dissertação (Mestrado em Psicologia Cognitiva) - Universidade Federal de Pernambuco, p.119. Recife, PE, 1994.

; ROSA, E. C. S. A leitura de textos literários na sala de aula: é conversando que a gente se entende. In: PAIVA, A.; MACIEL, F.; COSSON, R. (Org.) Literatura e formação de leitores do ensino fundamental. Coleção Explorando o ensino. Brasília: MEC/SEB, 2010, p. 69-88.

Entrando na roda: as histórias na Educação Infantil. In:

(Org.). Ler e escrever na Educação Infantil: discutindo práticas pedagógicas. 2. ed. Belo Horizonte, Autêntica, 2011, p. 33-51. 
CASTANHA, M. A linguagem no livro sem texto. In: OLIVEIRA, I. O que é qualidade em ilustração no livro infantil e juvenil: com a palavra o ilustrador. 1. ed. São Paulo, DCL, 2008 p. 141-160.

COSSON, R. Círculos de leitura e letramento literário. 1. ed. São Paulo Contexto, 2014.

FERNANDES, C. R. D. Letramento literário no contexto escolar. In: GONÇALVES A. V.; PINHEIRO A. S. (Org.). Nas trilhas do letramento: entre teoria, prática e formação docente. 1. ed. Campinas, Mercado de Letras, 2011, p. 321-348.

IBIAPINA, I. M. L. M. Pesquisa Colaborativa: Investigação, Formação e Produção de Conhecimentos. 1. ed. Brasília: Líber Livro, 2008.

MARTINS, M. S. C. Linguagem Infantil: oralidade, escrita e gêneros do discurso. In: ARCE, A; MARTINS, L. M. (Org.). Quem tem medo de ensinar na Educação Infantil? Em defesa do ato de ensinar. 3. ed. São Paulo, Alínea, 2007, p. 147-162.

OLIVEIRA, A. A. Textos visuais e as mediações escolares: desenvolver a sensibilidade da criança. In: MACHADO, M. Z. V; PAIVA, A; MARTINS, A. A; PAULINO, G. (Org.). EscoIhas literárias em jogo 1. ed. Belo Horizonte, Ceale, Autêntica, 2009, p.169-179.

RITER, C. A formação do leitor literário em casa e na escola. 1. ed. São Paulo, Biruta, 2009.

VIGOTSKI, L. S. Imaginação e criação na infância. Ensaio psicológico: livro para professores. São Paulo: Ática, 2009, p.135.

Fabiana Andrade de Santana: Graduada em Pedagogia pela Universidade Federal de Pernambuco. Tem experiência na área de Educação Infantil, e, em especial, no campo de leitura de textos literários. Atualmente participa como voluntária no projeto- LEIA: Leitura e Intervenção Literária em casa de acolhimento.

E-mail: fabiandrade31@hotmail.com

Ana Carolina Perrusi Brandão: Doutora em Psicologia pela University of Sussex (2004). É professora associada do Centro de Educação da Universidade Federal de Pernambuco (UFPE). Interessa-se por estudos na área de leitura e escrita na Educação Infantil, bem como sobre o ensino da compreensão de textos nas séries iniciais do Ensino Fundamental. É membro do Centro de Estudos em Educação e Linguagem (CEEL ( UFPE), onde desenvolve atividades de formação de professores e de produção e análise de materiais didáticos.

E-mail: carol.perrusi@ufpe.br 
